\title{
Arsenic Requires Sphingosine-1-Phosphate Type 1 Receptors to Induce Angiogenic Genes and Endothelial Cell Remodeling
}

\author{
Adam C. Straub, ${ }^{*}$ Linda R. Klei, ${ }^{*}$ Donna B. Stolz, ${ }^{\dagger}$ \\ and Aaron Barchowsky* \\ From the Departments of Environmental and Occupational \\ Health," and Cell Biology and Physiology, ${ }^{\dagger}$ University of \\ Pittsburgh, Pittsburgh, Pennsylvania
}

Arsenic in drinking water is a major public health concern as it increases risk and incidence of cardiovascular disease and cancer. Arsenic exposure affects multiple vascular beds, promoting liver sinusoidal capillarization and portal hypertension, ischemic heart disease, peripheral vascular disease, and tumor angiogenesis. While Rac1-GTPase and NADPH oxidase activities are essential for arsenic-stimulated endothelial cell signaling for angiogenesis or liver sinusoid capillarization, the mechanism for initiating these effects is unknown. We found that arsenic-stimulated cell signaling and angiogenic gene expression in human microvascular endothelial cells were Pertussis toxin sensitive, indicating a G-protein coupled signaling pathway. Incubating human microvascular endothelial cells with the sphingosine-1-phosphate type 1 receptor $\left(\mathrm{S1P}_{1}\right)$ inhibitor VPC23019 or performing small interfering RNA knockdown of S1P Slocked $_{1}$ block arsenic-stimulated HMVEC angiogenic gene expression and tube formation, but did not affect induction of either HMOX1 or IL8. Liver sinusoidal endothelial cells (LSECs) defenestrate and capillarize in response to aging and environmental oxidant stresses. We found that $\mathrm{S1P}_{1}$ was enriched on LSECs in vivo and in primary cell culture and that VPC23019 inhibited both sphingosine-1-phosphate-stimulated and arsenic-stimulated LSEC oxidant generation and defenestration. These studies identified novel roles for $\mathrm{S1P}_{1}$ in mediating arsenic stimulation of both angiogenesis and pathogenic LSEC capillarization, as well as demonstrating a role for $\mathbf{S 1 P}_{1}$ in mediating environmental responses in the liver vasculature, providing possible mechanistic insight into arsenic-induced vascular pathogenesis and disease. (Am J Pathol 2009, 174:1949-1958; DOI: 10.2353/ajpath.2009.081016)
Exposure to arsenic in drinking water increases risk and incidence of a number of cardiovascular pathologies and diseases including acute myocardial infarctions, ${ }^{1}$ cardiac ischemic disease, ${ }^{2}$ peripheral vascular disease, ${ }^{2}$ liver vascular diseases, and hypertension. ${ }^{3,4}$ Increased activity of vascular NADPH oxidase (Nox) enzymes that generate reactive oxygen species (ROS) often play a central role in the pathogenesis of these diseases, ${ }^{5,6}$ and arsenic rapidly stimulates both endothelial ${ }^{7,8}$ and smooth muscle ${ }^{9}$ Nox enzymes. Rac1 is an essential component of the arsenic-stimulated Nox complex ${ }^{7}$ and is a key regulator of endothelial cell migration in angiogenesis. ${ }^{5,10}$ As with endogenous G-protein coupled receptor (GPCR)mediated activation of Nox2-based oxidase, arsenic-stimulated oxidase activity requires Rac1- or Cdc42-GTPase activity and arsenic stimulates membrane translocation of Rac1 in both cultured endothelial cells $s^{7,8,11}$ and in vivo. ${ }^{12}$ However, no GPCR has been identified that responds to arsenic and the mechanism(s) through which arsenic stimulates this Rac1-mediated signaling have not been identified.

The present studies investigate arsenic-stimulated cell signaling through GPCR in endothelial cells from two vascular beds that produce different pathogenic responses when exposed to arsenic. The rationale for using two disparate endothelial phenotypes was to address whether arsenic activates heterogenic endothelium through common pathways. The first model was human microvascular cells (HMVEC) that produce angiogenic responses to arsenic. ${ }^{11,13}$ Arsenic stimulates microvascular angiogenesis in several in vivo models, and low environmental concentrations of arsenic enhance tu-

Supported by NIEHS grant ES013781 (to A.B.), NCI grant CA76541 (to D.B.S.), EPA STAR Fellowship FP-91654201 (to A.S.), and an internal grant from the Office of the Senior Vice Chancellor for the Health Sciences, University of Pittsburgh.

A.C.S. and L.R.K. contributed equally to this work.

Accepted for publication January 22, 2009

Address reprint requests to Aaron Barchowsky, Ph.D., Department of Occupational and Environmental Health, Graduate School of Public Health, University of Pittsburgh, Bridgeside Point, 100 Technology Dr., rm332, Pittsburgh, PA 15219. E-mail: aab20@pitt.edu. 
mor growth. ${ }^{14-17}$ The second model was mouse liver sinusoidal endothelial cells (LSECs). LSECs are highly specialized endothelial cells with fenestrations organized into sieve plates to provide a dynamic filtration system. ${ }^{18-20}$ This filtration facilitates exchange of lipoproteins, nutrients, and macromolecules between the blood stream and the hepatocytes. LSEC membranes contain a highly active scavenger receptor system that provides the major site of clearance for modified albumin, hyaluronin, and advance glycation end products from the blood. ${ }^{18-20}$ In aging and in response to various oxidizing environmental stimuli, ${ }^{18-20}$ including arsenic, ${ }^{12,21,22}$ the LSECs undergo capillarization, a maturation process in which the cells defenestrate, develop a basement membrane, and up-regulate expression of junctional platelet endothelial cell adhesion molecule (PECAM)-1. ${ }^{18-21}$ This process promotes the conversion of the discontinuous sinusoidal endothelium into a continuous lining with tight intercellular junctions and limited fenestrations. Capillarization has been associated with increased risk of systemic atherogenesis, as well as being a requisite precursor for hepatic fibrosis. ${ }^{18-20}$

Since we previously demonstrated that Rac1 mobilization, oxidase activation, oxidant generation, and oxidative signaling all occur within the first minutes of arsenic exposure in large vessel endothelial cells, the current studies examined the hypothesis that this signaling is receptor initiated. These studies provide novel demonstration that the $\mathrm{S}_{1} \mathrm{P}_{1}$ receptor is an integral component of pathogenic arsenic signaling that is common in different endothelial cell types. The functional outcome of this signaling, however, is dictated by the different phenotypes and physiological roles of the two cell types. In addition to identifying novel pathways for the vascular response to this environmental toxicant, these studies are also the first to indicate a pathophysiological role for $\mathrm{S}_{1} \mathrm{P}_{1}$ in LSEC capillarization.

\section{Materials and Methods}

\section{Mice}

Animal exposures were performed in agreement with institutional guidelines for animal safety and welfare at the University of Pittsburgh. C57BL/6-Tac (Taconic, Germantown, NY) male mice weighing $\sim 25 \mathrm{~g}$ were untreated or exposed to $100 \mu \mathrm{g} / \mathrm{L}$ of sodium arsenite in their drinking water for 2 weeks, as previously described. ${ }^{12,21,22}$ This level of arsenic is ten times above the regulated limit of human exposure and has been demonstrated to significantly increase risk of cardiovascular disease.

\section{Cell Cultures}

HMVECs (Lonza, Walkersville, MD) were cultured essentially as according to the supplier's instructions at 5\% $\mathrm{CO}_{2}$ in complete MCDB 131 medium (Invitrogen, Carlsbad, CA.) supplemented with EGM-2 MV SingleQuot (Lonza). At confluence, the growth factors were reduced by a 1:5 dilution of complete medium with basal MCDB
131, and all experiments were conducted 18 to 24 hours later. LSECs were isolated from the non-parenchymal cell fraction of collagenase digested C57BL/6 mouse livers and cultured on gelatin-coated coverslips, as previously described. ${ }^{21,23,24}$ Ex vivo sodium arsenite (ThermoFisher Scientific, Lafayette, CO) exposures ranged from 1 to 5 $\mu \mathrm{mol} / \mathrm{L}$, which was previously shown not to be cytotoxic. ${ }^{25}$ Sphingosine-1-phosphate (Cayman Chemical Co, Ann Arbor, MI) was added to HMVEC or LSEC at a final concentration of $1 \mu \mathrm{mol} / \mathrm{L}$. For small interfering (si)RNA knockdown experiments, $80 \%$ confluent cells were transfected with $40 \mathrm{nmol} / \mathrm{L}$ ON-TARGETplus SMARTpool of 4 siRNA sequences to human S1PR1 or $40 \mathrm{nmol} / \mathrm{L}$ nontargeting siRNA pool (ThermoFisher Scientific) using Lipofectamine 2000 and Opti-MEM (Invitrogen) reagents. After 4 days, the cells were placed in reduced medium for 18 hours before being exposed to sodium arsenite (As[III]). Cells were incubated with Pertussis toxin or the Rac1-selective inhibitor NSC23766 overnight before addition of arsenic to allow sufficient time for ADP ribosylation of $\mathrm{Gi}$ or incorporation of inhibitor into the Rac1GTPase guanine nucleotide exchange factor binding site, ${ }^{26}$ respectively.

\section{Microscopy and Quantitative Imaging}

Frozen liver sections and cultured cells were prepared for fluorescence imaging and scanning electron microscopy (SEM), as previously described. ${ }^{21,24}$ Quantitative measure of porosity (percentage of open area of fenestrations) was performed by measuring open fenestration area relative to total cell area in five $\times 10,000$ images from each coverslip of treated or non-treated cells, using MetaMorph v.7.0 software. The percent porosity calculated in the five images was averaged to give a single value per coverslip and all experiments were performed on three separate LSEC isolations with two coverslips from each isolation per treatment. Quantitative fluorescence analysis for immunostained PECAM-1 or hydroethidium was performed, as described. ${ }^{21,24}$ Three $\times 400$ images from six individual coverslips were used to quantify the $\%$ of thresholded pixels and further normalized to the $\%$ of thresholded nuclei. Antibodies for imaging included: rat monoclonal anti-mouse PECAM-1/CD31 (Becton Dickenson); $\mathrm{H}-60$ affinity purified polyclonal anti-S1P 1 (Santa Cruz Biotechnology); and Goat anti-rat Alexia 594 (Invitrogen), Goat anti-rabbit Alexa 488 (Invitrogen), and DRAQ5 (Biostatus, Leicestershire, UK) were used to stain nuclei.

\section{Reverse Transcription-PCR and Quantitative Real-Time PCR}

Total mouse liver or cellular HMVEC RNA was isolated with TRIzol reagent (Invitrogen, Carlsbad, CA) and $1 \mu \mathrm{g}$ was reverse-transcribed with MMLV (Promega, Madison, $\mathrm{WI}$ ). PCR for S1P receptor transcripts was performed for 30 cycles in an MJ Research PT-100 thermal cycler using previously published primers sets for human ${ }^{27}$ or mouse $^{28}$ S1P receptors or the house keeping gene 
RPL13A ${ }^{11}$ (human) and Hypoxanthine guanine phosphoribosyl transferase (HPRT) (mouse). For quantitative realtime-PCR, reverse transcribed cDNA was carried forward into real time PCR with SYBR greene master mix (Invitrogen, Carlsbad, CA) using an Opticon II DNA engine equipped with a continuous fluorescence detection system (BioRad, Hercules, Ca). RPL13A transcript levels were used for normalization. Interleukin (IL)8, heme oxygenase (decycling)1 (HMOX1), and RPL13A primer sequences were as published. ${ }^{11}$ Hepatocyte growth factor (HGF) (PPH00163B detecting transcripts of NM 000601) primers were from SuperArray Bioscience Corp (Frederick, MD) and insulin-like growth factor-1 (IGF1) (HS_IGF1_1_Sg detecting transcripts of NM 000618) primers were from Qiagen (Valencia, CA). SuperArray human angiogenesis $\mathrm{RT}^{2}$ Profiler PCR arrays (\#PAHS-024) specific for the Opticon II format were used to detect changes in HMVEC angiogenic genes.

\section{Rac1-GTPase Activity}

HMVEC Rac1-GTPase activity was determined with a G-LISA Rac1 activation assay (Cytoskeleton, Denver, CO). Briefly, after treatments, cells were placed on ice and washed twice with ice-cold PBS. The cells were lysed and scraped before being snap frozen in liquid $\mathrm{N}_{2}$. Buffer blanks and constitutively active Rac1 were included as negative and positive controls, respectively. Samples for G-LISA's were performed in triplicate and substrate color absorbance was read at $490 \mathrm{~nm}$ in a microplate reader. Data are expressed as Rac1 signal absorbance in samples minus the buffer blank.

\section{Superoxide Detection}

Primary LSECs were loaded with $5 \mu \mathrm{mol} / \mathrm{L}$ dihydroethidium (Invitrogen) for 10 minutes before adding arsenic for 30 minutes. The cells were then fixed with $4 \%$ paraformaldehyde and stained with DRAQ5. Dihydroethidium is converted to fluorescent hydroethidium in the presence of superoxide and arsenic-stimulated hydroethidium fluorescence is completely blocked in LSEC treated with the superoxide scavenger Tempol. ${ }^{21}$

\section{Western Analysis}

SDS-polyacrylamide gel electrophoresis separation of total liver, LSEC, or HMVEC proteins and immunoblotting were performed using NuPage Novex $4 \%$ to $12 \%$ Bis-Tris gels (Invitrogen), as previously published. ${ }^{11}$ Membranes were probed with $\mathrm{H}-60$ anti-S1 $\mathrm{P}_{1}$ and monoclonal anti- $\beta$ actin (Sigma) followed by goat or donkey anti-rabbit horseradish peroxidase-conjugated secondary antibodies (Amersham Bioscience UK, Buckinghamshire, UK).

\section{Matrigel Vascular Tube Formation Assays}

In vitro endothelial cell tube formation assays in three dimensional Matrigel (Becton Dickinson) cultures (performed as described ${ }^{11}$ ) were used to measure arsenic stimulation of migration and initiation of an angiogenic response. Branch points of rhodamine-phalloidin (Molecular Probes, Invitrogen, Carlsbad, CA) stained endothelial cell tubes were quantified in $\times 40$ images using MetaMorph v.7.0 software.

\section{Statistics}

One- or two-way analysis of variance was used to identify significant differences $(P<0.05)$ between treatment groups and controls. The degree of significance between groups was then compared using Bonferroni's posttest for multiple comparisons. All statistics were performed using GraphPad Prism, v5.0 software (GraphPad Software, San Diego, CA). Data are presented as means \pm $\mathrm{SD}$ or SEM of quantified values or fold relevant control.

\section{Results}

\section{Ptx Inhibits Arsenic-Stimulated HMVEC Activation}

Arsenic stimulates rapid translocation of Rac1 to the membrane and oxidant generation in large vessel endothelial cells. ${ }^{7,29}$ The data in Figure $1 \mathrm{~A}$ confirm that arsenic exposure rapidly activates HMVEC Rac1 GTPase activity. Specificity of the assay for Rac1 activity is demonstrated by inhibition of the arsenic response in cells treated with NSC23766 (iRac). Ptx, a Gi/o-selective inhibitor, prevented arsenite-stimulated Rac1 activity (Figure 1B), implicating a Gi/o receptor in mediating the arsenite response. Note that neither inhibitor affected basal Rac1activity, since NSC23766 prevents Rac1 interaction with quanine exchange factors that increase basal activity ${ }^{26}$ and Ptx prevents upstream signals that activate these same factors. Pre-treating HMVEC with either Ptx or NSC23766 prevented arsenic from increasing IL8 transcripts within a 4 hours period (Figure $1 \mathrm{C}$ ), indicating a functional linkage pathway between arsenic stimulated Gi/o and gene induction. Interestingly, neither Ptx nor NSC23766 pretreatments prevented arsenic from inducing stress responsive HMOX1 transcripts (Figure 1D). Quantitative PCR transcript arrays were used to investigate the extent of arsenic-stimulated, Ptx-inhibitable effects on inducible angiogenic gene transcripts. Arsenic exposure increased or repressed only 7 of the 84 transcripts contained on the array (Table 1). Ptx alone had positive and negative effects on many more transcript levels (data not shown). However, when arsenic effects in untreated and Ptx-treated cells were compared for fold stimulation, Ptx was shown to block arsenic effects on all 7 responsive genes (Table 1).

\section{Antagonizing S1P Receptors Prevents Arsenite-Stimulated HMVEC Activation}

Gi/o-linked S1P receptors promote endothelial cell migration and spreading in angiogenesis. Pre-incubating HMVEC with VPC23019, a selective competitive inhibitor of the S1P and $\mathrm{S} \mathrm{P}_{3}$ receptors, ${ }^{30}$ prevented both arsenic-increased 
A

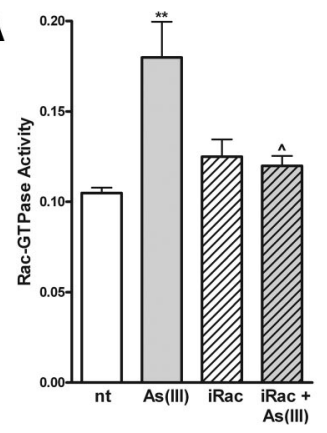

B
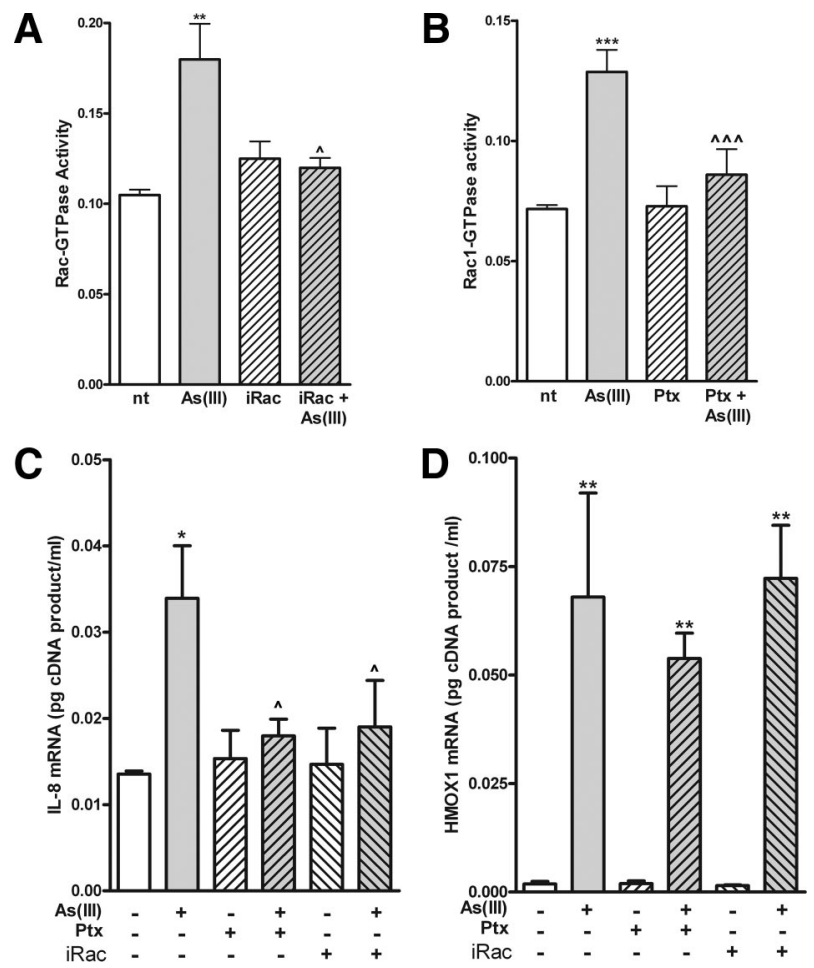

Figure 1. G-protein coupled and Rac1 mediated HMVEC responses to arsenic. The effect of $5 \mu \mathrm{mol} / \mathrm{L}$ arsenic, as As(III), on HMVEC Rac1-GTPase activity in the presence or absence of (A) $100 \mu \mathrm{mol} / \mathrm{L}$ NSC23766 (iRac) or (B) $50 \mathrm{ng} / \mathrm{ml} \mathrm{Ptx}$ is shown. Both inhibitors were added 18 to 24 hours before As(III) and As(III) exposures were for 6 minutes. Similar pre-treatments with the inhibitors were used to examine the roles of Rac1 and $\mathrm{Gi} / \mathrm{o}$ coupled receptors on increases in IL8 and HMOX1 transcript levels stimulated by 4 hours, $5 \mu \mathrm{mol} / \mathrm{L}$ As(III) exposures. Values for transcript levels shown in (C) and (D) are standardized to transcript levels for the housekeeping gene, RPL13A. All data are presented as mean \pm SEM with four biological replicates for Rac1 activity and thrree for transcript levels. Data were analyzed by one-way analysis of variance and Bonferroni's posthoc test. ${ }^{*} P<0.05$, ${ }^{* *} P<0.01,{ }^{*}{ }^{*}{ }^{* * * * *} P<$ 0.001 versus non-treated (nt) cells. ${ }^{\wedge} P<0.05,{ }^{\wedge} \wedge P<0.001$ versus arsenic- or S1P-stimulated responses in the absence of inhibitors.

HGF and IGF-1 transcript levels (Figure 2A) and tube formation in Matrigel cushions (Figure 2B). VPC23019 also inhibited HGF, IGF1, and IL8 induction by the endogenous ligand, S1P (Figure 2A). In contrast, S1P did not induce

Table 1. PCR Array for Angiogenic Genes in Following 24 Hours Exposures to Arsenite with or without Ptx

\begin{tabular}{lcc}
\hline \multirow{2}{*}{ Proangiogenic genes } & \multicolumn{2}{c}{ Fold control } \\
\cline { 2 - 3 } & \multicolumn{1}{c}{ As(III) } & As(III) + Ptx \\
\hline CXCL3 & $1.74 \pm 0.10^{\ddagger}$ & $1.06 \pm 0.06^{\|}$ \\
Hepatocyte growth factor & $4.20 \pm 0.38^{\dagger}$ & $1.89 \pm 0.17^{\dagger}$ \\
Insulin-like growth factor1 & $2.47 \pm 0.63^{\dagger}$ & $1.10 \pm 0.16^{\boldsymbol{\eta}}$ \\
Interleukin8 & $2.23 \pm 0.60^{\dagger}$ & $0.80 \pm 0.16^{\pi}$ \\
Anti-angiogenic genes & & \\
Transforming growth factor $\beta$ & $0.37 \pm 0.06^{\ddagger}$ & $0.7 \pm 0.01^{ \pm \|}$ \\
CXCL9 & $0.46 \pm 0.13^{\dagger}$ & $0.69 \pm 0.23^{\star \S}$ \\
\hline
\end{tabular}

Data are presented as mean \pm SEM fold over untreated or Ptxtreated control for PCR products normalized to housekeeping gene expression. Ptx $(50 \mathrm{ng} / \mathrm{ml})$ was added for 18 hours prior to adding 1 $\mu \mathrm{mol} / \mathrm{L}$ As(III), after which the cells were incubated for an additional 24 hours. Significant differences, determined by one-way ANOVA, from control values as indicated: ${ }^{\star} P<0.05,{ }^{\dagger} P<0.01$, or ${ }^{\ddagger} P<0.001$. Differences between $\mathrm{As}(\mathrm{III})$ effects in the presence or absence of Ptx are designated by ${ }^{\S} P<0.05,{ }^{\natural} P<0.01$, or $\| P<0.001$ ( $n=3$ biological replicates).
A
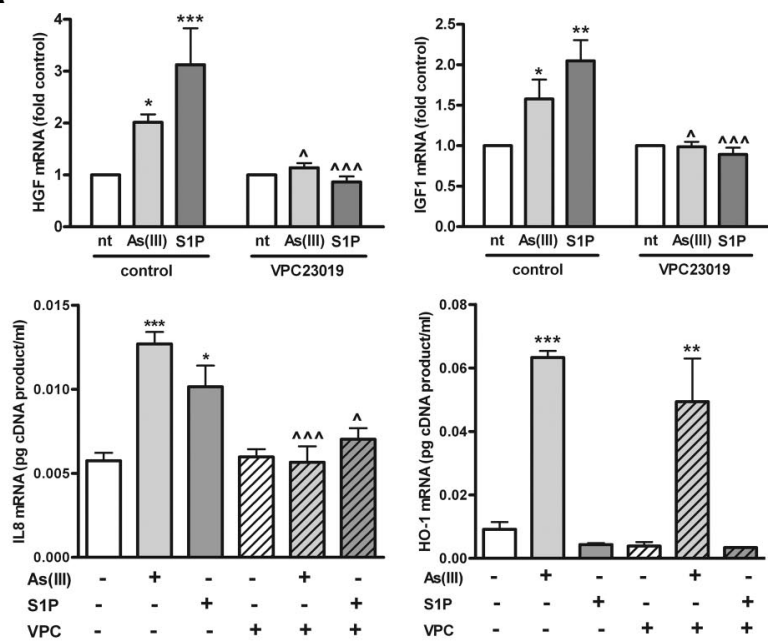

B
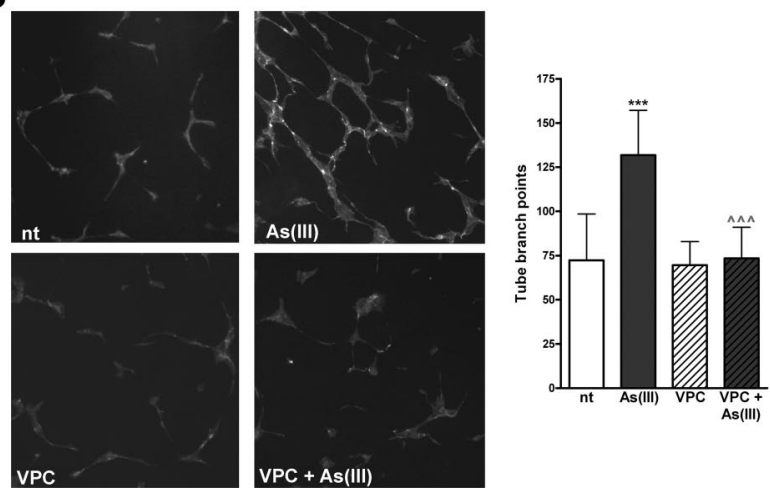

Figure 2. Selective inhibition of arsenic-stimulated HMVEC gene expression and vascular tube formation by VPC23019. A: Basal and stimulated transcript levels for representative angiogenic (HGF and IGF1), chemokine (IL8), and adaptive (HMOX1) genes were quantified in RNA extracts from non-treated HMVEC or HMVEC pre-treated for 30 minutes with $1 \mu \mathrm{mol} / \mathrm{L}$ VPC23019. All transcript levels are standardized to RPL13A transcript levels. The cells were stimulated with $1 \mu \mathrm{mol} / \mathrm{L}$ of either As(III) or sphingosine-1-phosphate for 4 hours. B: Cells plated on Matrigel cushions were treated with VPC23109 and/or As(III) as in (A). At the end of the 4 hours As(III) exposure, the cushions were fixed and stained with rhodamine-phalloidin before fluorescent imaging at a magnification of $\times 40$. The branch points in the tube networks were enumerated and the data in the graph are presented as mean \pm SEM branch points in eight biological replicates. Data were analyzed by one- (B) or two-way (A) analysis of variance and Bonferroni's posthoc test. ${ }^{*} P<0.05,{ }^{* * *} P<0.01,{ }^{*}{ }^{*} \cdot{ }^{*} * P<0.001$ versus non-treated $(\mathrm{nt})$ cells. ${ }^{\wedge} P<$ $0.05,{ }^{\wedge} P<0.001$ versus arsenic- or S1P-stimulated responses in the absence of inhibitors.

HMOX1 and VPC23019 did not prevent arsenic from increasing HMOX1 transcript levels (Figure 2A).

As expected for microvascular endothelial cells, ${ }^{31-33}$ $\mathrm{S}_{1} \mathrm{P}_{1}$ was the most abundantly expressed $\mathrm{S} 1 \mathrm{P}$ receptor in the HMVECs (Figure 3A), with $\mathrm{S}_{1} \mathrm{P}_{3}$, and possibly $\mathrm{S} \mathrm{P}_{4}$ being modestly expressed. Neither arsenic nor S1P increased HMVEC S1P 1 transcript levels (Figure 4B and transcript array [data not shown]). Cells transfected for 4 days with $\mathrm{S}_{1} \mathrm{P}_{1}$-selective siRNA, but not random siRNA, had both reduced $\mathrm{S}_{1} \mathrm{P}_{1}$ transcript and protein levels (Figures 3B). S1P $\mathrm{P}_{1}$ knockdown blocked arsenite-stimulated Rac1 activity (Figure 3C) and attenuated arsenite-induced HGF and IGF-1 transcript levels (Table 2). However, eliminating $\mathrm{S} \mathrm{P}_{1}$ did not prevent arsenite-increased IL8 or HMOX1 transcript levels. More importantly, S1P 
A

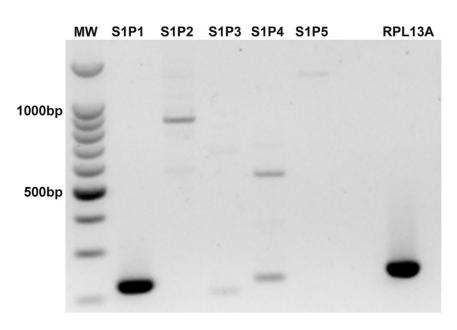

C

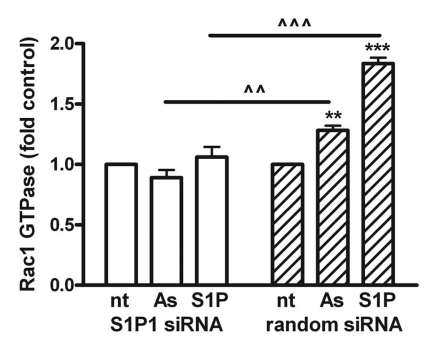

B

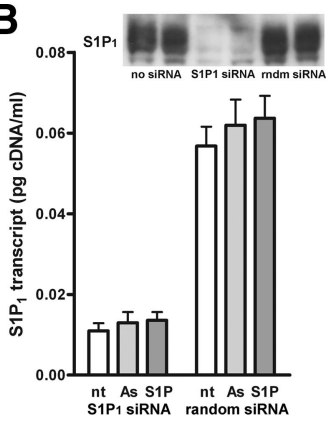

D

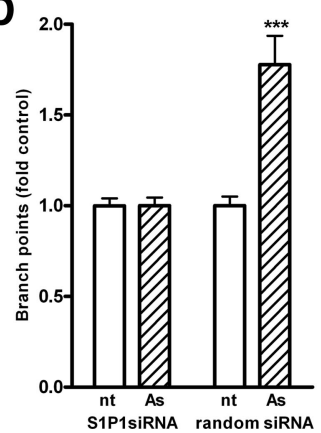

Figure 3. HMVEC $\mathrm{S}_{1} \mathrm{P}_{1}$ expression and its role in arsenic-stimulated Rac1 activation and vascular tube formation. A: The relative transcript levels of S1P receptors and RPL13A, a house keeping gene, in $1 \mu \mathrm{g}$ of HMVEC RNA were measured after 30 cycles of conventional RT-PCR. B: S1P ${ }_{1}$ protein (top panel) and transcript levels (graph) were measured 4 days after transfection with either $\mathrm{S}_{1} \mathrm{P}_{1}$-specific or random siRNA sequences. Transcript levels were measured by quantitative real time RT-PCR and normalized to RPL13A transcript levels. In addition, the graph also presents the lack of effects of 4-hour exposures on either $1 \mu \mathrm{mol} / \mathrm{L}$ As(III) or S1P on $\mathrm{S}_{1} \mathrm{P}_{1}$ transcript levels. The effects of 4-day transfections with $\mathrm{S}_{1} \mathrm{P}_{1}$-specific or random siRNA sequences on basal or As(III)- or S1P-stimulated Rac1 (C) or (D) vascular tube formation are shown. Rac1 activity was quantified as in Figure 1 and tube branch formation as in Figure 2. All data in the graphs are presented as mean \pm SEM with four biological replicates for $\mathrm{S}_{1} \mathrm{P}_{1}$ transcript levels and Rac1 activity and eight biological replicates for branch point enumeration. Data were analyzed by one-way analysis of variance and Bonferroni's posthoc test. ${ }^{* * *} P<0.01$, ${ }^{* * * *} P<0.001$ versus non-treated (nt) cells. ${ }^{\wedge} P<0.01,{ }^{\wedge}{ }^{\wedge} P<0.001$ versus arsenic- or S1P-stimulated responses in the absence of inhibitors.

knockdown prevented arsenite-stimulated tube formation, indicating that $\mathrm{S}_{1} \mathrm{P}_{1}$ is the major pro-angiogenic receptor responding to arsenic (Figure 3D).

\section{$S 1 P_{1}$ is Highly Expressed on LSEC}

Little is known of the role of S1P receptors or S1P signaling in the liver or the liver sinusoids. In liver sections excised from untreated mice or mice exposed for 2 weeks to $100 \mu \mathrm{g} / \mathrm{L}$ arsenic in their drinking water, $\mathrm{S}_{1} \mathrm{P}_{1}$ protein appeared to be predominantly expressed in the sinusoidal vessel endothelium, relative to large vessel endothelium or hepatocytes (Figure 4A). In addition, S1P is also highly expressed in the hepatic arteries and in the lymphatic regions of the peribiliary vascular plexus. The arsenic exposure was sufficient to cause LSEC defenestration and capillarization in vivo, ${ }^{21,22}$ but had no significant on $\mathrm{S}_{1} \mathrm{P}_{1}$ protein or transcript levels in whole liver or in isolated LSEC (Figure 4). S1P 1 protein levels were relatively low in total liver protein extracts, but highly enriched in freshly isolated LSECs (Figure 4C). Staining for $\mathrm{S} 1 \mathrm{P}_{3}$ protein in the liver sections was negative (data not shown), which was

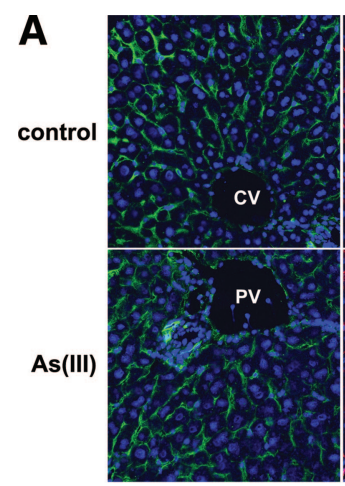

S1P1

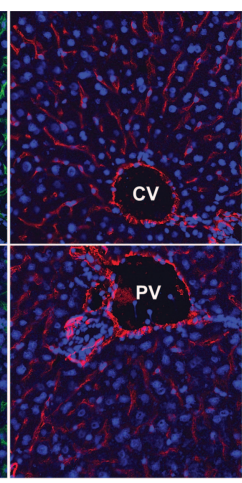

PECAM-1

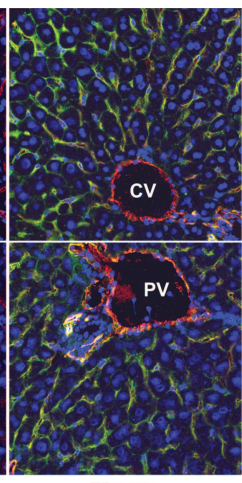

Merge
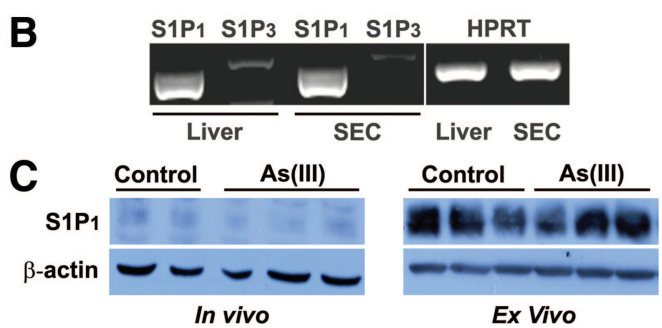

Figure 4. $\mathrm{S}_{\mathrm{P}} \mathrm{P}_{1}$ is highly expressed on LSEC and does not change after arsenic exposure. A: Liver sections from control mice and mice exposed for 2 weeks to $100 \mu \mathrm{g} / \mathrm{L}$ of arsenic were immunostained for $\mathrm{S}_{1} \mathrm{P}_{1}$ (green channel), PECAM (red channel), and nuclei (blue channel). CV and PV designate a central and portal vein lumen respectively. B: Total liver RNA extracts from the same mice, as well as RNA extracts from purified LSECs, were assayed by RT-PCR for $\mathrm{S}_{1} \mathrm{P}_{1}, \mathrm{~S}_{1} \mathrm{P}_{3}$, or HPRT transcripts, as described in Materials and Methods. $\mathbf{C}$ : Total liver protein extracts from control or arsenic exposed mice, as well as control and ex vivo arsenic-exposed LSECs, were immunoblotted for $\mathrm{S}_{1} \mathrm{P}_{1}$ and $\beta$-actin. Ex vivo $2.5 \mu \mathrm{mol} / \mathrm{L}$ arsenic exposures lasted 24 hours. All lanes represent proteins from separate liver or cell extracts.

consistent with the extremely low amount of $\mathrm{S}_{1} \mathrm{P}_{3}$ transcript levels in either the total liver or the purified LSECs.

\section{Ptx Inhibits Arsenic-Stimulated LSEC Defenestration}

Exposure of mice to arsenic in drinking water caused persistent association of Rac1 with mouse LSEC membranes $^{12}$ and treating isolated LSECs with NSC23766 prevented arsenic-stimulated defenestration. ${ }^{21}$ To examine whether Gi/o activation was also upstream of the Rac1 mediated defenestration pathway, freshly isolated

Table 2. Effect of siRNA on As(III) or S1P Stimulated Transcript Levels

\begin{tabular}{lccccc}
\hline & \multicolumn{2}{c}{ Transcript levels (mean \pm SEM fold control) } \\
\cline { 2 - 3 } \cline { 5 - 6 } Gene & As & \multicolumn{2}{c}{ S1P ${ }_{1}$ siRNA } & & \multicolumn{2}{c}{ Random siRNA } \\
\cline { 2 - 3 } \cline { 5 - 6 } HGF & $1.1 \pm 0.1$ & $1.3 \pm 0.1$ & & $1.8 \pm 0.1^{* \dagger}$ & $2.1 \pm 0.1^{* \dagger}$ \\
IGF1 & $1.4 \pm 0.1$ & $1.0 \pm 0.1$ & & $2.3 \pm 0.3^{* \dagger}$ & $1.6 \pm 0.1^{* \dagger}$ \\
IL8 & $3.8 \pm 0.3^{*}$ & $3.3 \pm 0.5^{*}$ & & $3.4 \pm 0.3^{*}$ & $2.7 \pm 0.2^{*}$ \\
HMOX1 & $18.9 \pm 2.9^{*}$ & $2.3 \pm 0.7$ & & $20.2 \pm 3.1^{*}$ & $3.2 \pm 0.5$ \\
\hline
\end{tabular}

Cells were transfected with the indicated siRNA for 4 days and then incubated overnight in reduced growth factor medium. The cells were then stimulated with $1 \mu \mathrm{mol} / \mathrm{L}$ of $\mathrm{As}(\mathrm{III})$ or S1P for 4 hours, before isolating total RNA for quantitative PCR for the indicated transcripts. ${ }^{*}=$ difference $(P<$ 0.01) from non-stimulated control; ${ }^{\dagger}=$ difference $(P<0.01)$ from corresponding stimulation in cells treated with $\mathrm{S}_{1} \mathrm{P}_{1}$ SiRNA. Data were analyzed by two-way ANOVA, $n=4$ biological replicates. 

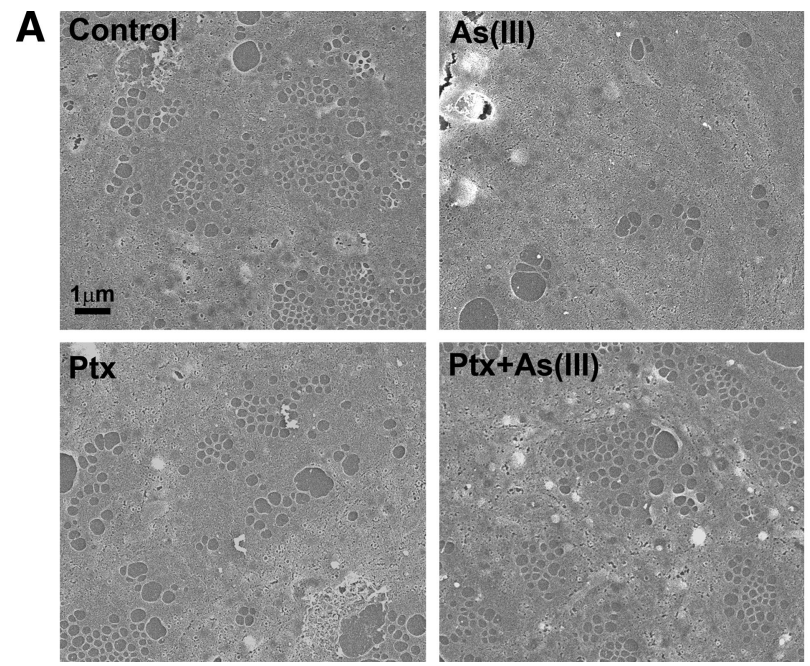

LSECs were treated with Ptx and the porosity of the cells was examined 24 hours later. Treatment of LSECs for 24 hours with Ptx in the absence of arsenic had no effect on fenestrations. In contrast, the data in Figure 5A,B demonstrate that Ptx prevented arsenic-induced LSEC differentiation and defenestration. Thus, Gi/o receptor activity is not required for basal maintenance of the LSEC phenotype, but increased Gi/o activity is a common proximal step in arsenic-stimulated functional morphological change in both LSECs and HMVECs.
B

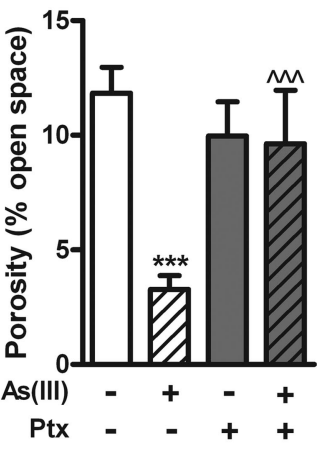

Figure 5. Arsenic-stimulated LSEC defenestration is inhibited with Ptx. A: Representative SEM images were captured from LSECs that were treated with Ptx and As(III) for 8 hours. B: Morphometric analysis was used to determine the percentage of open space (porosity) of five $\times 10,000$ images from five individual coverslips. The graph represents the mean \pm SD $\%$ of sinusoidal porosity. Data were analyzed by one-way analysis of variance and Bonferroni's posthoc test. ***** $P<0.001$ versus nontreated (nt) cells. ${ }^{\wedge \wedge} P<0.001$ versus arsenic- or S1P-stimulated responses in the absence of inhibitors.

\section{Antagonizing S1P, Inhibits Arsenic-Stimulated Oxidant Generation and Defenestration}

To examine the role of $\mathrm{S}_{1} \mathrm{P}_{1}$ in arsenic-stimulated LSEC defenestration, isolated primary cells were incubated with either arsenic or S1P in the presence of absence of VPC23019. Arsenic was as effective as the endogenous ligand in reducing porosity and increasing junctional PECAM-1 expression (Figure 6A) and VPC23019 inhibited the responses to both agonists (Figure 6, B-D). VPC23019
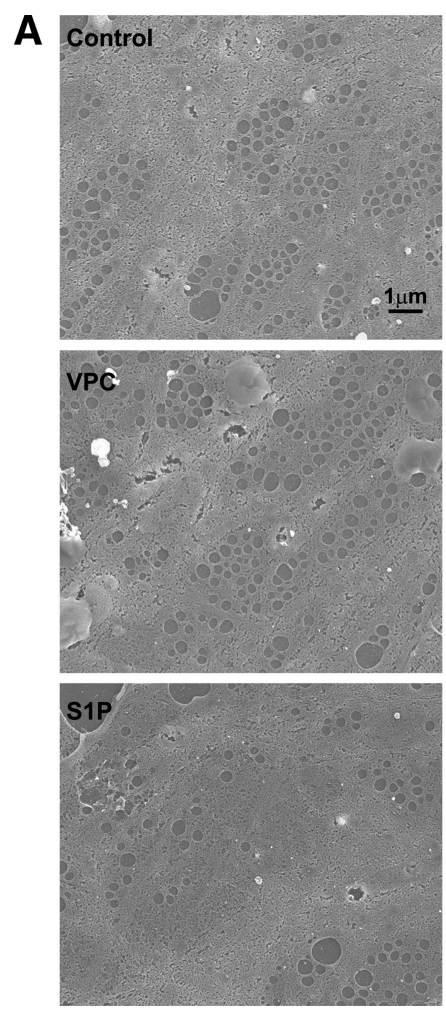
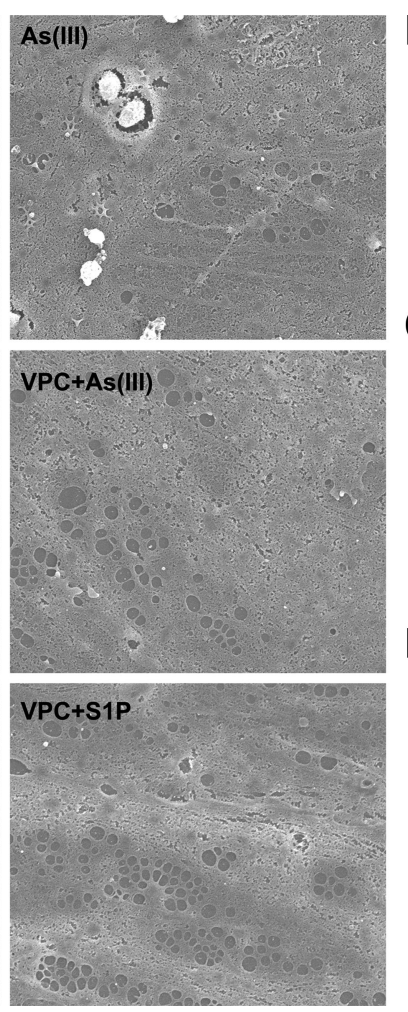

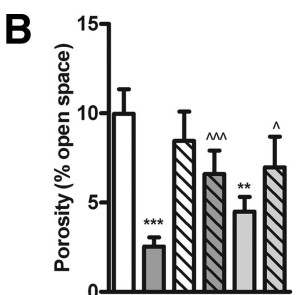

C

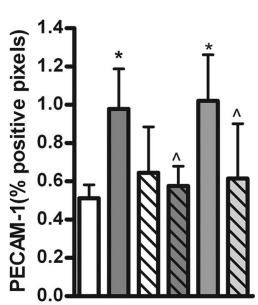

D

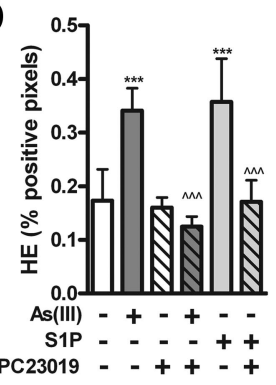

Figure 6. VPC23019 limits arsenic-induced LSEC defenestration. A: SECs isolated from mice were pre-incubated with $1 \mu \mathrm{mol} / \mathrm{L}$ VPC23019 for 1 hour before adding $2.5 \mu \mathrm{mol} / \mathrm{L}$ As(III) or 1 $\mu \mathrm{mol} / \mathrm{L}$ S1P for 8 hours. At the end of the exposures, cells were fixed for SEM imaging and quantitative analysis. All images were taken at $\times 10,000$. B: Porosity was quantified in five images taken from each of five individual coverslips. Data in the graph are the mean \pm SD of average LSEC porosity on the coverslips $(n=5)$ C: In separate LSEC isolates, PECAM-1 surface expression relative to nuclear staining was measured using quantitative morphometric analysis of immunostained coverslips. The data are presented as the mean \pm SD of the average $\%$ of PECAM-1/DRAQ5 threshold pixel density from cells on five coverslips. D: LSECs on coverslips were pretreated with dihydroethidium for 10 minutes before adding $2.5 \mu \mathrm{mol} / \mathrm{L}$ arsenic or 1 $\mu \mathrm{mol} / \mathrm{L}$ S1P for 30 minutes. The cells were then fixed and imaged for hydroethidium and DRAQ5 fluorescence. The graph presents mean \pm SD of the average $\%$ of hydroethidium/DRAQ5 threshold pixel density from cells on five coverslips. Data were analyzed by one-way analysis of variance and Bonferroni's posthoc test. ${ }^{*} P<0.05$, ${ }^{* *} P<0.01,{ }^{* * * *} P<0.001$ versus non-treated (nt) cells. ${ }^{\wedge} P<0.05,{ }^{\wedge}{ }^{\wedge} P<0.001$ versus arsenic- or S1P-stimulated responses in the absence of inhibitors. 
was also effective in preventing either arsenic or S1P from increasing LSEC superoxide generation (Figure 6D), which we have previously demonstrated to be essential for arsenicstimulated defenestration. ${ }^{21}$

\section{Discussion}

The mechanisms for initiating signaling in response to non-cytotoxic levels of arsenic in vascular cells or any other cell type are relatively unknown. Since responses of vascular cells to arsenic, such as Rac1 activation and $\mathrm{NADPH}$ oxidase generation of superoxide, can be as rapid and robust as to endogenous GPCR ligands, ${ }^{7,11}$ the present study investigated the hypothesis that arsenic acts through a cell surface receptor to stimulate signal amplification cascades. Several endothelial cell GPCRs that stimulate Nox enzymes, cell migration, and angiogenesis link to Rac1 activation through Gi/o. ${ }^{5,31,34-36}$ The data are consistent with a requirement for Gi/o-coupled $\mathrm{S}_{1} \mathrm{P}_{1}$ in arsenic-stimulated pro-angiogenic and remodeling responses of two distinct types of endothelial cells. $\mathrm{S}_{1} \mathrm{P}_{1}$ is the dominant pro-migratory and angiogenic member of the S1P receptor family ${ }^{31,33,35}$ and proved essential for arsenic to induce angiogenic gene expression in HMVEC. More importantly, $\mathrm{S}_{1} \mathrm{P}_{1}$ was required for arsenic to stimulate HMVEC migration and tube formation, initial steps in angiogenesis. In addition to promoting angiogenesis in de-

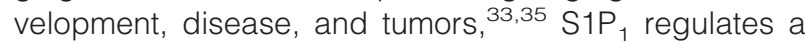
range of cardiovascular functions including heart rate, blood pressure, and barrier functions. ${ }^{31,35}$ Thus, it is possible that $\mathrm{S} \mathrm{P}_{1}$ - and oxidant-dependent ${ }^{21}$ defenestration of LSEC may represent a gain in barrier function as the cells differentiate toward the phenotype of a continuous endothelium.

The data presented here suggest that arsenic acts selectively on the $\mathrm{S} \mathrm{P}_{1}$ receptor to elicit signal transduction and phenotypic change. $\mathrm{S}_{1} \mathrm{P}_{1}$ activation is a known endogenous risk factor for cardiovascular disease and tumorigenesis. Genetic deletion of $\mathrm{S} \mathrm{P}_{1}$ is embryonic lethal with pronounced defects in angiogenesis, endothelial barrier function, and vascular tone. ${ }^{35,37}$ Arsenic acts in a manner similar to S1P, the cognate ligand for the $\mathrm{S}_{1} \mathrm{P}_{1}$, in activating endothelial cell Rac1 and Nox enzyme activities. The levels of arsenic used in these studies were not cytotoxic ${ }^{21,25,29}$ and the resulting amounts of ROS generated were more regulatory than stressful. ${ }^{21,29} \mathrm{Ar}$ senic stimulates Nox enzyme-mediated ROS generation in all forms of endothelial cells examined, ${ }^{21,29,38}$ as well as in smooth muscle cells. ${ }^{9}$ S1P also activates vascular cell Nox enzymes, although this effect may be cell type specific. Increased Nox-enzyme oxidant production and oxidant-dependent cell migration was reported for S1Pstimualted smooth muscle cells, ${ }^{39,40}$ but not for venous endothelium. ${ }^{41}$ We demonstrated that both arsenic- and S1P-stimulated LSEC oxidant production was inhibited by a competitive antagonist of $\mathrm{S}_{1} \mathrm{P}_{1}$ and $\mathrm{S}_{1} \mathrm{P}_{3}$ receptors, VPC23019. It is possible that the LSECs generate oxidants in response to S1P relative to the cultured venous endothelial cells ${ }^{41}$ due to a difference in receptor expression and/or culture conditions, since the both cell types require the gp91-based Nox2 enzyme to generate oxidants for remodeling. ${ }^{6,21,41,42}$ The data presented here and in previous reports ${ }^{7,21,38}$ suggest that Nox enzymederived superoxide and downstream ROS are the second messengers for these GPCR mediated effects of arsenic. In addition to arsenic-induced ROS activating downstream signaling kinases and transcription factors, ${ }^{38}$ they may have additional actions by decreasing nitric oxide levels that are essential for maintaining normal endothelial cell functions. Thus, arsenic appears to stimulate endothelial cell dysfunction through a conventional pathogenic signaling cascade leading from a GPCR to increased regulatory oxidant-mediated signaling.

The mechanism for arsenic activation of the receptor was not revealed in the current studies. However, trivalent arsenite readily reacts with cysteine thiols ${ }^{43-45}$ and it is possible that arsenic reaction with one or more of the thirteen cysteine thiols in $\mathrm{S} \mathrm{P}_{1}$ may allosterically activate the receptor. Precedence for such regulation comes from the ability of s-nitrosylation of cysteines in various GPCRs to affect either receptor affinity for ligand or interactions with regulators of G-protein coupling. ${ }^{46-48}$ Cysteine thiols are critical for dictating quaternary structure of GPCRs, ligand affinity in binding pockets, and lipid interactions with intracellular loop domains. Effects of S-nitrosylation on $\mathrm{S}_{1} \mathrm{P}_{1}$ have not been reported and the role of $\mathrm{S} \mathrm{P}_{1}$ cysteines in receptor function has not been extensively studied. In other receptors, such as the M4 acetylcholine receptor, nitrosylation of thiols increases both ligand affinity and receptor activity. ${ }^{46}$ For $\mathrm{S}_{1} \mathrm{P}_{1}$, mutation of cysteine 5.44 in the fifth transmembrane domain and ligand binding pocket of $\mathrm{S}_{1} \mathrm{P}_{1}$ increases ligand $\mathrm{EC}_{50}$ and reduces receptor efficacy. ${ }^{49}$ Thus, it is plausible that arsenic acting in a similar manner to nitric oxide and reacting with cysteine 5.44 or another critical $\mathrm{S}_{1} \mathrm{P}_{1}$ thiol could activate the receptor. Unfortunately, nitrosylation of thiols in the lysophosphatidic acid type 1 or angiotensin II type 1 receptors decreases ligand binding affinity. ${ }^{46,50}$ Thus, detailed investigation of arsenic interactions with the multiple cysteines in $\mathrm{S}_{1} \mathrm{P}_{1}$ will be needed to examine whether these interactions are responsible for receptor activation. It is less likely that arsenic interactions with $\mathrm{Gi} / \mathrm{o}$, regulators of $\mathrm{Gi} / \mathrm{o}$, or proteins involved in receptor turnover could explain the specific actions of arsenic on Rac1 activation, angiogenesis, or LSEC defenestration. Such an action would be expected to link multiple Gi/olinked receptors to downstream signaling and that would be only partially inhibited by VPC23019 or S1P 1 siRNA knockdown.

The hypothesis that arsenic activates vascular remodeling responses by interacting with $\mathrm{S}_{1} \mathrm{P}_{1}$ thiols does not exclude the likelihood that interactions with thiols in other receptors or signaling proteins mediating arsenic-induced endothelial cell phenotypic change or adaptation. We found that activating $\mathrm{S}_{1} \mathrm{P}_{1}$ does not account for all Ptx-sensitive HMVEC signaling stimulated by arsenic, such as pathways for induction of $I L 8$ transcripts. The fact that IL8 induction was inhibited by both Ptx and VPC23019, but not S1P 1 siRNA, is consistent with previous observations that combined $\mathrm{S}_{1} \mathrm{P}_{1}$ and $\mathrm{S}_{1} \mathrm{P}_{3}$ receptor activation is necessary to produce full effects of S1P on 
chemokine expression ${ }^{32}$ and endothelial functions. ${ }^{31,35}$ We previously found that IL8 and products other NF- $\kappa \mathrm{B}$ driven genes are not needed for arsenite initial tube formation. ${ }^{11}$ However, a full Ptx-sensitive response to arsenite may be needed for complete vessel remodeling in vivo where inflammatory and supporting cell recruitment is required for sustained vessel development. ${ }^{51,52}$ Nonetheless, $\mathrm{S1P}_{1}$ appears to be an essential initiator of arsenite-stimulated HMVEC signaling for angiogenic effects. In contrast, inhibiting or eliminating $\mathrm{S}_{\mathrm{P}} \mathrm{P}_{1}$ does not prevent arsenic effects on endothelial adaptive or stress pathways. The stress pathway leading to HMOX1 induction may involve arsenic ${ }^{43}$ or ROS binding to Keap $1,{ }^{53,54}$ a thiol-containing scaffold protein, which allows Nrf2 nuclear translocation and transactivation of the HMOX1 promoter. ${ }^{55,56}$

In addition to novel demonstration of receptor-mediated signaling in response to arsenic, the findings in Figures 4-6 are the first indication that $\mathrm{S}_{\mathrm{P}} \mathrm{P}_{1}$ has a role in pathogenic differentiation of LSEC into a capilliarized endothelium. LSEC capillarization is a form of cell differentiation that occurs in aging and following certain oxidizing environmental exposures, ${ }^{18-20}$ but is not necessarily a cytotoxic event. Livers from mice exposed to 100 $\mu \mathrm{g} / \mathrm{L}$ of arsenic appeared normal, other than having reduced sinusoidal porosity. ${ }^{12,21,22}$ The data in Figure 5 are the first to indicate that $\mathrm{S}_{1} \mathrm{P}_{1}$ protein expression is limited to the LSEC relative to large liver vessel endothelium. There appeared to be no S1P $\mathrm{P}_{1}$ expression in hepatocytes, which may explain the low protein expression detected by Western analysis of total liver protein extracts (Figure 4C). The images do not exclude the presence of $\mathrm{S}_{1} \mathrm{P}_{1}$ on stellate cells, which have previously been shown to express the receptor and increase proliferation in response to S1P. ${ }^{57}$ However, stellate cells are eliminated from the LSEC cultures. Arsenic was as effective as S1P in stimulating LSEC defenestration and oxidant generation in the cultured LSEC (Figure 6) and these responses were inhibited by VPC23019. In keeping with a previous report of $\mathrm{S}_{1} \mathrm{P}_{1}$ being essential for full endothelial cell PECAM-1 expression, ${ }^{58}$ antagonizing $\mathrm{S}_{1} \mathrm{P}_{1}$ prevented arsenic-stimulated junctional PECAM-1 protein expression that is required for increased cell contacts in LSEC capillarization (Figure 6). Thus, activation of $\mathrm{S}_{1} \mathrm{P}_{1}$, either by arsenic or endogenous ligand, leads to potentially pathogenic remodeling of the LSEC and possibly activation of stellate cells. ${ }^{57}$ The high level of receptor expression in normal, fenestrated LSECs suggests that the receptor may be up-regulated because it is either not functionally signaling or endogenous ligand is limited. Given that both arsenic and S1P increase oxidant production in these cells within minutes, it is more likely that ligand availability is the rate-limiting factor regulating fenestrations. This hypothesis is supported by recent evidence that S1P release in the liver is very low and overexpression of liver sphingosine kinase 1, which generates S1P from sphingosine, restores circulating S1P in sphingosine kinase null mice. ${ }^{59,60}$ Cultured LSEC were shown to avidly release S1P. ${ }^{59,60}$ However, it is difficult to maintain the fenestrated LSEC phenotype in culture and it is not clear whether S1P release was measured in fenestrated or defenestrated LSECs. ${ }^{60}$ In vivo, the physiological stimulus for release of endothelial S1P is shear-stress from blood flow. ${ }^{59}$ Thus, ligand release may be reduced under the low perfusion pressure and low shear conditions of the normal liver sinusoids. However, up-regulation of the receptor may prime the sinusoids to respond to an environ-

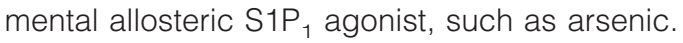

In summary, inappropriate activation of $\mathrm{S} \mathrm{P}_{1}$ may promote selective molecular effects of arsenic in vascular diseases and tumorigenesis. Identifying a GPCR signaling pathway as being essential for arsenic signaling in endothelial cell activation provides a novel paradigm shift in the understanding of arsenic-related vascular pathogenesis. Stimulation of the type 1 sphingosine-1-phosphate receptor appears to be a common mechanism for arsenic-initiated signaling for endothelial cell morphological and phenotypic changes in both angiogenic responses and in pathogenic gain of barrier function in the liver vasculature. The role for $\mathrm{S}_{1} \mathrm{P}_{1}$ activation in the LSEC has not been previously reported. Thus, these data both identify a novel mechanism for the vascular effects of arsenic and reveal fundamental regulatory mechanisms of liver sinusoidal vasculature.

\section{Acknowledgments}

We thank Dr. Simon Watkins of the Center for Biological Imaging for SEM and confocal microscopy use. We thank Dr. Timothy Billiar and his laboratory for providing nonparenchymal cell fractions for LSEC isolations.

\section{References}

1. Yuan Y, Marshall G, Ferreccio C, Steinmaus C, Selvin S, Liaw J, Bates $\mathrm{MN}$, Smith $\mathrm{AH}$ : Acute myocardial infarction mortality in comparison with lung and bladder cancer mortality in arsenic-exposed region II of Chile from 1950 to 2000. Am J Epidemiol 2007, 166:1381-1391

2. Wang CH, Hsiao CK, Chen CL, Hsu LI, Chiou HY, Chen SY, Hsueh YM, Wu MM, Chen CJ: A review of the epidemiologic literature on the role of environmental arsenic exposure and cardiovascular diseases. Toxicol Appl Pharmacol 2007, 222:315-326

3. Chen Y, Factor-Litvak P, Howe GR, Graziano JH, Brandt-Rauf P, Parvez F, van Geen A, Ahsan H: Arsenic exposure from drinking water. Dietary intakes of B vitamins and folate, and risk of high blood pressure in Bangladesh: a population-based, cross-sectional study. Am J Epidemiol 2007, 165:541-552

4. Kwok RK, Mendola P, Liu ZY, Savitz DA, Heiss G, Ling HL, Xia Y Lobdell D, Zeng D, Thorp Jr JM, Creason JP, Mumford JL: Drinking water arsenic exposure and blood pressure in healthy women of reproductive age in Inner Mongolia. China Toxicol Appl Pharmacol 2007, 222:337-343

5. Hordijk PL: Regulation of NADPH oxidases: the role of Rac proteins. Circ Res 2006, 98:453-462

6. Lee MY, Griendling KK: Redox signaling, vascular function, and hypertension. Antioxid Redox Signal 2008, 10:1045-1059

7. Smith KR, Klei LR, Barchowsky A: Arsenite stimulates plasma membrane NADPH oxidase in vascular endothelial cells. Am J Physiol 2001, 280:L442-L449

8. Qian Y, Liu KJ, Chen Y, Flynn DC, Castranova V, Shi X: Cdc42 regulates arsenic-induced NADPH oxidase activation and cell migration through actin filament reorganization. J Biol Chem 2005, 280: 3875-3884

9. Lynn S, Gurr JR, Lai HT, Jan KY: NADH oxidase activation is involved in arsenite-induced oxidative DNA damage in human vascular smooth muscle cells. Circ Res 2000, 86:514-519 
10. Tan W, Palmby TR, Gavard J, Amornphimoltham P, Zheng Y, Gutkind JS: An essential role for Rac1 in endothelial cell function and vascular development. FASEB J 2008, 22: 1829-1838

11. Klei LR, Barchowsky A: Positive signaling interactions between arsenic and ethanol for angiogenic gene induction in human microvascular endothelial cells. Toxicol Sci 2008, 102:319-327

12. Straub AC, Stolz DB, Ross MA, Hernandez-Zavala A, Soucy NV, Klei LR, Barchowsky A: Arsenic stimulates sinusoidal endothelial cell capillarization and vessel remodeling in mouse liver. Hepatology 2007 45:205-212

13. Basu P, Ghosh RN, Grove LE, Klei L, Barchowsky A: Angiogenic potential of 3-nitro-4-hydroxy benzene arsonic acid (roxarsone). Environ Health Perspect 2008, 116:520-523

14. Soucy NV, Ihnat MA, Kamat CD, Hess L, Post MJ, Klei LR, Clark C, Barchowsky A: Arsenic stimulates angiogenesis and tumorigenesis in vivo. Toxicol Sci 2003, 76:271-279

15. Soucy NV, Mayka D, Klei LR, Nemec AA, Bauer JA, Barchowsky A Neovascularization and angiogenic gene expression following chronic arsenic exposure in mice. Cardiovasc Toxicol 2005, 5:29-42

16. Kamat CD, Green DE, Curilla S, Warnke L, Hamilton JW, Sturup S, Clark C, Innat MA: Role of HIF signaling on tumorigenesis in response to chronic low-dose arsenic administration. Toxicol Sci 2005 86:248-257

17. Liu B, Pan SG, Dong XS, Qiao HQ, Jiang HC, Krissansen GW, Sun XY: Opposing effects of arsenic trioxide on hepatocellular carcinomas in mice. Cancer Science 2006, 97:675-681

18. DeLeve LD: Hepatic microvasculature in liver injury. Semin Liver Dis $2007,27: 390-400$

19. Elvevold K, Smedsrod B, Martinez I: The liver sinusoidal endothelial cell: a cell type of controversial and confusing identity. Am J Physiol Gastrointest Liver Physiol 2008, 294:G391-G400

20. Le Couteur DG, Cogger VC, McCuskey RS, de Cabo R, Smedsrod B, Sorensen KK, Warren A, Fraser R: Age-related changes in the liver sinusoidal endothelium: a mechanism for dyslipidemia. Ann NY Acad Sci 2007, 1114:79-87

21. Straub AC, Clark KA, Ross MA, Chandra AG, Li S, Gao X, Pagano PJ Stolz DB, Barchowsky A: Arsenic-stimulated liver sinusoidal capillarization in mice requires NADPH oxidase-generated superoxide. J Clin Invest 2008, 118:3980-3989

22. Straub AC, Stolz DB, Vin H, Ross MA, Soucy NV, Klei LR, Barchowsky A: Low level arsenic promotes progressive inflammatory angiogenesis and liver blood vessel remodeling in mice. Toxicol Appl Pharmacol 2007, 222:327-336

23. Seglen PO: Preparation of isolated rat liver cells. Methods Cell Biol 1976, 13:29-83

24. Ross MA, Sander CM, Kleeb TB, Watkins SC, Stolz DB: Spatiotemporal expression of angiogenesis growth factor receptors during the revascularization of regenerating rat liver. Hepatology 2001, 34:1135-1148

25. Barchowsky A, Dudek EJ, Treadwell MD, Wetterhahn KE: Arsenic induces oxidant stress and NF-kappaB activation in cultured aortic endothelial cells. Free Radic Biol Med 1996, 21:783-790

26. Gao Y, Dickerson JB, Guo F, Zheng J, Zheng Y: Rational design and characterization of a Rac GTPase-specific small molecule inhibitor. Proc Natl Acad Sci USA 2004, 101:7618-7623

27. Balthasar S, Samulin J, Ahlgren H, Bergelin N, Lundqvist M, Toescu EC, Eggo MC, Tornquist K: Sphingosine 1-phosphate receptor expression profile and regulation of migration in human thyroid cancer cells. Biochem J 2006, 398:547-556

28. Skaznik-Wikiel ME, Kaneko-Tarui T, Kashiwagi A, Pru JK: Sphingosine-1-phosphate receptor expression and signaling correlate with uterine prostaglandin-endoperoxide synthase 2 expression and angiogenesis during early pregnancy. Biol Reprod 2006, 74:569-576

29. Barchowsky A, Klei LR, Dudek EJ, Swartz HM, James PE: Stimulation of reactive oxygen, but not reactive nitrogen species, in vascular endothelial cells exposed to low levels of arsenite. Free Radic Biol Med 1999, 27:1405-1412

30. Davis MD, Clemens JJ, Macdonald TL, Lynch KR: Sphingosine 1-phosphate analogs as receptor antagonists. J Biol Chem 2005 280:9833-9841

31. Peters SL, Alewijnse AE: Sphingosine-1-phosphate signaling in the cardiovascular system. Curr Opin Pharmacol 2007, 7:186-192

32. Lin $\mathrm{Cl}$, Chen CN, Lin PW, Lee H: Sphingosine 1-phosphate regulates inflammation-related genes in human endothelial cells through S1P1 and S1P3. Biochem Biophys Res Commun 2007, 355:895-901

33. Chae SS, Paik JH, Furneaux H, Hla T: Requirement for sphingosine 1-phosphate receptor-1 in tumor angiogenesis demonstrated by in vivo RNA interference. J Clin Invest 2004, 114:1082-1089

34. Richard DE, Vouret-Craviari V, Pouyssegur J: Angiogenesis and Gprotein-coupled receptors: signals that bridge the gap. Oncogene 2001, 20:1556-1562

35. Brinkmann V: Sphingosine 1-phosphate receptors in health and disease: mechanistic insights from gene deletion studies and reverse pharmacology. Pharmacol Ther 2007, 115:84-105

36. Gonzalez E, Kou R, Michel T: Rac1 modulates sphingosine 1-phosphate-mediated activation of phosphoinositide 3-kinase/Akt signaling pathways in vascular endothelial cells. J Biol Chem 2006, 281: 3210-3216

37. Allende ML, Yamashita T, Proia RL: G-protein-coupled receptor S1P1 acts within endothelial cells to regulate vascular maturation. Blood 2003, 102:3665-3667

38. Barchowsky A, Roussel RR, Klei LR, James PE, Ganju N, Smith KR, Dudek EJ: Low levels of arsenic trioxide stimulate proliferative signals in primary vascular cells without activating stress effector pathways. Toxicol Appl Pharmacol 1999, 159:65-75

39. Catarzi S, Giannoni E, Favilli F, Meacci E, lantomasi T, Vincenzini MT Sphingosine 1-phosphate stimulation of NADPH oxidase activity: relationship with platelet-derived growth factor receptor and c-Src kinase. Biochim Biophys Acta 2007, 1770:872-883

40. Roztocil E, Nicholl SM, Davies MG: Sphingosine-1-phosphate-induced oxygen free radical generation in smooth muscle cell migration requires Galpha12/13 protein-mediated phospholipase C activation. J Vasc Surg 2007, 46:1253-1259

41. Ushio-Fukai M, Tang Y, Fukai T, Dikalov SI, Ma Y, Fujimoto M, Quinn MT, Pagano PJ, Johnson C, Alexander RW: Novel role of gp91(phox)-containing $\mathrm{NAD}(\mathrm{P}) \mathrm{H}$ oxidase in vascular endothelial growth factor-induced signaling and angiogenesis. Circ Res 2002 91:1160-1167

42. Ushio-Fukai M, Alexander RW: Reactive oxygen species as mediators of angiogenesis signaling: role of $\mathrm{NAD}(\mathrm{P}) \mathrm{H}$ oxidase. Mol Cell Biochem 2004, 264:85-97

43. Kitchin KT, Wallace K: The role of protein binding of trivalent arsenicals in arsenic carcinogenesis and toxicity. J Inorg Biochem 2008 102:532-539

44. Lu M, Wang $H$, Wang $Z$, Li XF, Le XC: Identification of reactive cysteines in a protein using arsenic labeling and collision-induced dissociation tandem mass spectrometry. J Proteome Res 2008, 7:3080-3090

45. Carter DE, Aposhian HV, Gandolfi AJ: The metabolism of inorganic arsenic oxides, gallium arsenide, and arsine: a toxicochemical review. Toxicol Appl Pharmacol 2003, 193:309-334

46. Kokkola T, Savinainen JR, Monkkonen KS, Retamal MD, Laitinen JT: S-nitrosothiols modulate $\mathrm{G}$ protein-coupled receptor signaling in a reversible and highly receptor-specific manner. BMC Cell Biol 2005, 6:21

47. Wess J, Han SJ, Kim SK, Jacobson KA, Li JH: Conformational changes involved in G-protein-coupled-receptor activation. Trends Pharmacol Sci 2008, 29:616-625

48. Ozawa K, Whalen EJ, Nelson CD, Mu Y, Hess DT, Lefkowitz RJ, Stamler JS: S-nitrosylation of beta-arrestin regulates beta-adrenergic receptor trafficking. Mol Cell 2008, 31:395-405

49. Fujiwara Y, Osborne DA, Walker MD, Wang DA, Bautista DA, Liliom K, Van Brocklyn JR, Parrill AL, Tigyi G: Identification of the hydrophobic ligand binding pocket of the S1P1 receptor. J Biol Chem 2007 282:2374-2385

50. Leclerc PC, Lanctot PM, Auger-Messier M, Escher E, Leduc R, Guillemette G: S-nitrosylation of cysteine 289 of the AT1 receptor decreases its binding affinity for angiotensin II. Br J Pharmacol 2006, 148:306-313

51. Albini A, Tosetti F, Benelli R, Noonan DM: Tumor inflammatory angiogenesis and its chemoprevention. Cancer Res 2005, 65:1063710641

52. Ramsauer M, D'Amore PA: Getting Tie(2)d up in angiogenesis. J Clin Invest 2002, 110:1615-1617

53. Pi J, Qu W, Reece JM, Kumagai Y, Waalkes MP: Transcription factor 
Nrf2 activation by inorganic arsenic in cultured keratinocytes: involvement of hydrogen peroxide. Exp Cell Res 2003, 290:234-245

54. He X, Chen MG, Lin GX, Ma Q: Arsenic induces NAD(P)H-quinone oxidoreductase I by disrupting the Nrf2 $\times$ Keap $1 \times$ Cul3 complex and recruiting Nrf2 $\times$ Maf to the antioxidant response element enhancer. J Biol Chem 2006, 281:23620-23631

55. Alam J, Cook JL: Transcriptional regulation of the heme oxygenase-1 gene via the stress response element pathway. Curr Pharm Des 2003, 9:2499-2511

56. Gong P, Stewart D, Hu B, Vinson C, Alam J: Multiple basic-leucine zipper proteins regulate induction of the mouse heme oxygenase-1 gene by arsenite. Arch Biochem Biophys 2002, 405:265-274

57. Ikeda H, Yatomi Y, Yanase M, Satoh H, Maekawa H, Ogata I, Ozaki Y, Takuwa Y, Mochida S, Fujiwara K: Biological activities of novel lipid mediator sphingosine 1-phosphate in rat hepatic stellate cells. Am J Physiol Gastrointest Liver Physiol 2000, 279:G304-G310

58. Krump-Konvalinkova V, Yasuda S, Rubic T, Makarova N, Mages J, Erl W Vosseler C, Kirkpatrick CJ, Tigyi G, Siess W: Stable knock-down of the sphingosine 1-phosphate receptor S1P1 influences multiple functions of human endothelial cells. Arterioscler Thromb Vasc Biol 2005, 25: $546-552$

59. Hla T, Venkataraman K, Michaud J: The vascular S1P gradientCellular sources and biological significance. Biochim Biophys Acta 2008, 1781:477-482

60. Venkataraman K, Lee YM, Michaud J, Thangada S, Ai Y, Bonkovsky HL, Parikh NS, Habrukowich C, Hla T: Vascular endothelium as a contributor of plasma sphingosine 1-phosphate. Circ Res 2008, 102:669-676 